\title{
Did I say that word or did you? Executive dysfunctions in schizophrenic patients affect memory efficiency, but not source attributions
}

Citation for published version (APA):

Peters, M. J. V., Cima, M. J., Smeets, T., de Vos, M., Jelicic, M., \& Merckelbach, H. L. G. J. (2007). Did I say that word or did you? Executive dysfunctions in schizophrenic patients affect memory efficiency, but not source attributions. Cognitive Neuropsychiatry, 12(5), 914-411.

https://doi.org/10.1080/13546800701470145

Document status and date:

Published: 01/01/2007

DOI:

10.1080/13546800701470145

Document Version:

Publisher's PDF, also known as Version of record

Please check the document version of this publication:

- A submitted manuscript is the version of the article upon submission and before peer-review. There can be important differences between the submitted version and the official published version of record.

People interested in the research are advised to contact the author for the final version of the publication, or visit the DOI to the publisher's website.

- The final author version and the galley proof are versions of the publication after peer review.

- The final published version features the final layout of the paper including the volume, issue and page numbers.

Link to publication

\footnotetext{
General rights rights.

- You may freely distribute the URL identifying the publication in the public portal. please follow below link for the End User Agreement:

www.umlib.nl/taverne-license

Take down policy

If you believe that this document breaches copyright please contact us at:

repository@maastrichtuniversity.nl

providing details and we will investigate your claim.
}

Copyright and moral rights for the publications made accessible in the public portal are retained by the authors and/or other copyright owners and it is a condition of accessing publications that users recognise and abide by the legal requirements associated with these

- Users may download and print one copy of any publication from the public portal for the purpose of private study or research.

- You may not further distribute the material or use it for any profit-making activity or commercial gain

If the publication is distributed under the terms of Article $25 \mathrm{fa}$ of the Dutch Copyright Act, indicated by the "Taverne" license above, 
This article was downloaded by:[University of Maastricht]

On: 15 August 2007

Access Details: [subscription number 781062704]

Publisher: Psychology Press

Informa Ltd Registered in England and Wales Registered Number: 1072954

Registered office: Mortimer House, 37-41 Mortimer Street, London W1T 3JH, UK

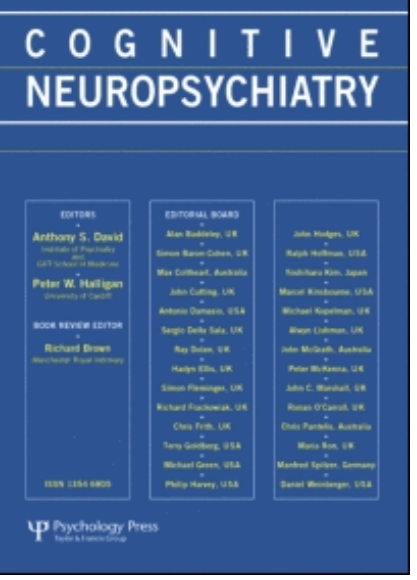

\section{Cognitive Neuropsychiatry}

Publication details, including instructions for authors and subscription information: http://www.informaworld.com/smpp/title content=t713659088

Did I say that word or did you? Executive dysfunctions in schizophrenic patients affect memory efficiency, but not source attributions

Online Publication Date: 01 September 2007

To cite this Article: Peters, Maarten J. V., Cima, Maaike J., Smeets, Tom, de Vos, Marije, Jelicic, Marko and Merckelbach, Harald (2007) 'Did I say that word or did you? Executive dysfunctions in schizophrenic patients affect memory efficiency, but not source attributions', Cognitive Neuropsychiatry, 12:5, 391 - 411

To link to this article: DOI: $10.1080 / 13546800701470145$

URL: http://dx.doi.org/10.1080/13546800701470145

\section{PLEASE SCROLL DOWN FOR ARTICLE}

Full terms and conditions of use: http://www.informaworld.com/terms-and-conditions-of-access.pdf

This article maybe used for research, teaching and private study purposes. Any substantial or systematic reproduction, re-distribution, re-selling, loan or sub-licensing, systematic supply or distribution in any form to anyone is expressly forbidden.

The publisher does not give any warranty express or implied or make any representation that the contents will be complete or accurate or up to date. The accuracy of any instructions, formulae and drug doses should be independently verified with primary sources. The publisher shall not be liable for any loss, actions, claims, proceedings, demand or costs or damages whatsoever or howsoever caused arising directly or indirectly in connection with or arising out of the use of this material.

(C) Taylor and Francis 2007 


\title{
Did I say that word or did you? Executive dysfunctions in schizophrenic patients affect memory efficiency, but not source attributions
}

\author{
Maarten J. V. Peters, Maaike J. Cima, Tom Smeets, \\ Marije de Vos, Marko Jelicic, and Harald Merckelbach \\ Department of Clinical Psychological Science, Faculty of Psychology, \\ Maastricht University, Maastricht, The Netherlands
}

\begin{abstract}
Introduction. Schizophrenic patients have difficulties in recognising previously presented verbal information and identifying its sources. The antecedents of these recognition and source misattributions are, however, largely unknown. The current study examined to what extent schizophrenic patients' lack of memory efficiency, their memory errors, and their source misattributions are related to neurocognitive deficits (i.e., executive dysfunctions).

Methods. 23 schizophrenic patients and 20 healthy controls were administered an adapted version of the Deese/Roediger-McDermott (DRM) task from which parameters of memory efficiency, memory errors, source misattributions, and two-high threshold measures were derived. Furthermore, two neurocognitive tasks tapping executive functions were administered: the Wisconsin Card Sorting Test (WCST) and the Behavioural Assessment of the Dysexecutive Syndrome (BADS). Using multiple linear regression analyses, we examined whether these neurocognitive measures predicted various memory parameters.

Results. Patients with schizophrenia showed poorer memory efficiency and were more prone to make internal-external source misattributions with high confidence. However, they did not more often falsely recognise critical lure words than controls. Executive dysfunctions predicted memory efficiency, but not source misattribution performance.

Conclusion. Our findings provide further evidence that schizophrenic patients' memory impairments are intimately related to fundamental neurocognitive deficits.
\end{abstract}

Correspondence should be addressed to Maarten J. V. Peters, Department of Clinical Psychological Science, Faculty of Psychology, Maastricht University, PO Box 616, 6200 MD, Maastricht, The Netherlands. E-mail: m.peters@psychology.unimaas.nl

This study was supported by a grant from the Dutch organisation for scientific research, N.W.O., grant number 452-02-006. We would like to thank Drs Mesotten and Bryon, psychologist Michael Hilderson, and other staff members of both psychiatric hospitals for their help with the data collection. We would like to thank editor Professor Anthony David, reviewer Dr Ayana Gibbs, and one anonymous reviewer for their constructive comments on the earlier versions of this manuscript.

(C) 2007 Psychology Press, an imprint of the Taylor \& Francis Group, an Informa business http://www.psypress.com/cogneuropsychiatry

DOI: $10.1080 / 13546800701470145$ 
Schizophrenia is known for its prominent cognitive deficits (Heinrichs \& Zakzanis, 1998). While memory performance of schizophrenic patients exhibits a wide range of impairments (Aleman, Hijman, de Haan, \& Kahn, 1999; McKenna, Ornstein, \& Baddeley, 2002), it is especially characterised by omission errors (i.e., misses). That is, schizophrenic patients have a tendency to omit or miss information when asked to recall or recognise specific verbal or nonverbal material (e.g., McKenna et al., 1990; Moritz, Woodward, Cuttler, Whitman, \& Watson, 2004; see Aleman et al., 1999, for a meta-analysis). However, because such omission errors can be observed in many psychiatric patients, recent research has tried to pinpoint memory aberrations that are more specific for schizophrenia (Aleman et al., 1999; McKenna, McKay, \& Laws, 2000). One memory aspect that seems to be markedly impaired in schizophrenia is source monitoring (Johnson, Hashtroudi, \& Lindsay, 1993). This refers to the ability to identify the source of remembered information, i.e., source attribution. Schizophrenic patients consistently show a deficiency in internal source attribution (e.g., "Did I do this or did I only imagine this?"; Nienow \& Docherty, 2004) and reality monitoring (e.g., "Did I say this or did someone else say this to me?"; Brébion et al., 2000; Brébion, Gorman, Amador, Malaspina, \& Sharif, 2002; Keefe, Arnold, Bayen, \& Harvey, 1999; Moritz, Woodward, \& Ruff, 2003; Vinogradov et al., 1997). Moritz et al. (2003) reported that, apart from their tendency to make source misattributions, schizophrenic patients also show exaggerated confidence in their source judgement capabilities.

Interestingly, recent studies (Elvevåg, Fisher, Weickert, Weinberger, \& Goldberg, 2004; Moritz et al., 2004; Weiss, Dodson, Goff, Schacter, \& Heckers, 2002) noted that schizophrenic patients' memory is superior to that of control individuals in one particular respect: Schizophrenic patients are less susceptible to experimentally induced false memories (i.e., false alarms of critical lures). For example, using the standard Deese/RoedigerMcDermott paradigm (DRM; Deese, 1959; Roediger \& McDermott, 1995) to elicit such false alarms, Moritz et al. (2004) found that compared to healthy controls, patients with schizophrenia produce relatively few false alarms when confronted with semantically related lures in a recognition task (e.g., they less often falsely recognise the never presented word sleep among a list of previously presented semantic associates like bed, rest, tired, and so on). However, in accordance with other studies, Moritz et al. also reported that schizophrenic patients tend to make many misses on the DRM task, while showing an increased confidence in these errors.

How can this pattern of memory aberrations typical for schizophrenia best be explained? A plethora of research has demonstrated a specific link between clinical symptomatology (positive and negative symptoms) and susceptibility to source misattributions (e.g., Brébion et al., 2000, 2002; Brébion, Gorman, Malaspina, \& Amador, 2005; see also Nienow \& 
Docherty, 2004, for similar findings). Moreover, recent studies demonstrated that source misattribution performance is partly dependent on intellectual ability (Vinogradov et al., 1997) and cognitive functions (e.g., verbal memory performance; Elvevåg et al., 2004; Moritz et al., 2003, 2004). In an attempt to integrate these findings, Brébion et al. (2005) investigated the relationships between verbal memory impairments, source misattribution, and automated cognitive functions, on the one hand, and clinical symptomatology, on the other. The authors looked at two memory systems: memory efficiency and memory errors. Memory efficiency refers to the number of correct responses and can be further subdivided into superficial and deep memory processing. Brébion et al. found that processing speed and selective attention serve as the primary antecedents of memory efficiency. Memory errors (false alarms to critical lures or new words) were found to be associated with positive and negative symptoms. These authors also noted that source misattributions affected memory errors directly and indirectly via positive symptomatology.

There are good reasons to believe that distinct neuropsychological deficits related to schizophrenia also affect memory efficiency and memory errors (see Peters, Jelicic, \& Merckelbach, 2006b, for a review). Indeed, Brébion et al. (2005) argued that as memory deficits (e.g., omission errors) observed in schizophrenia resemble those seen in patients with damage to the medial temporal lobe, schizophrenic patients have difficulties with deep memory processing during encoding (e.g., inefficient memory strategy). Alternatively, memory deficits in schizophrenia may be caused by executive dysfunctions. After all, an important aspect of executive functioning, which is subserved by a neural network encompassing primarily the prefrontal cortex, is monitoring the retrieval of encoded events in memory (e.g., Dodson \& Schacter, 2002; Johnson et al., 1993; Peters et al., 2006b). Because schizophrenic patients exhibit marked deficits on both executive and memory tasks (see McKenna et al., 2002; Weinberger et al., 2001), executive dysfunctions may explain memory impairments in schizophrenia over and above the contribution of symptomatology and medial temporal lobe dysfunctions (see Moritz et al., 2003; Vinogradov et al., 1997).

Most of the studies cited above looked at isolated memory dysfunctions in schizophrenic patients. That is, they specifically focused on schizophrenic patients' memory efficiency, memory errors, or source misattributions. The current study relied on a paradigm that allowed examining all these different memory dysfunctions simultaneously. We also explored how certain neurocognitive impairments are related to these dysfunctions because this may inform theories about the origins of schizophrenic patients' memory aberrations. More specifically, we explored whether executive control and working memory measured by the Wisconsin Card Sorting Test (Heaton, Chelune, Talley, Kay, \& Curtiss, 1993) and planning of behaviour indexed by 
the Behavioural Assessment of the Dysexecutive Syndrome (Wilson, Alderman, Burgess, Emslie, \& Evans, 1996) predict memory efficiency, memory errors, and source misattributions in schizophrenic patients and healthy controls.

A shortcoming of many previous studies in this domain (Moritz \& Woodward, 2002; Moritz et al., 2003, but see Moritz et al., 2004) is that they elicited low levels of experimentally induced false memories (i.e., false alarms). Hence, a laboratory task was employed that is known to elicit high levels of false memories, even in healthy controls. To this end, we used an adapted version of the DRM paradigm to simultaneously tap memory efficiency, memory errors, and source misattributions.

In keeping with previous work, we expected that, relative to controls, schizophrenic patients would display a decrease in memory efficiency and more source misattributions, while showing an increased confidence for these errors. Conversely, control participants were expected to commit more experimentally induced false memories (i.e., false alarms for critical lures) together with an increased confidence for the critical lure words. Most importantly, we tested whether executive dysfunctions related to the prefrontal cortex might statistically predict memory aberrations in schizophrenia.

\section{METHOD}

\section{Participants}

Twenty-three inpatients (18 men, 5 women) with a DSM-IV (Diagnostic and Statistical Manual of Mental Disorders, 4th edition; American Psychiatric Association, 1994) diagnosis of schizophrenia were recruited from two Belgian psychiatric hospitals: Medical Centre Sint-Jozef, Munsterbilzen and Public Psychiatric Centre, Rekem. Diagnoses were made by a panel of experienced psychiatrists on the basis of extensive diagnostic interviews, but prior to neurocognitive assessment. Sociodemographic information and clinical data are presented in Table 1 (see later). All patients were on fixed doses of antipsychotic medication, either typical $(86 \%)$ or atypical $(14 \%)$. Based on a thorough screening of the medical records, they were excluded if they had a history of severe neurological disorders, substance abuse, or another comorbid Axis 1 disorder.

Twenty healthy control participants (18 men, 2 women) were recruited from a pool of volunteers from Maastricht University and through advertisements in a local newspaper. Control participants were matched for age, gender, and level of education. They were screened with a semistructured interview to rule out a psychiatric history, neurological disorders, alcohol abuse, or drug addiction. None of the control participants 
TABLE 1

Demographic, symptomatological, and neurocognitive characteristics of schizophrenic and control participants

\begin{tabular}{lccc}
\hline & $\begin{array}{c}\text { Schizophrenic } \\
\text { patients }(n=23)\end{array}$ & $\begin{array}{c}\text { Control participants } \\
(n=20)\end{array}$ & Statistics \\
\hline Age & $36.30(13.13)$ & $35.20(9.71)$ & $t(41)=0.31 ; n s$ \\
Gender (men/women) & $18 / 5$ & $18 / 2$ & $\chi^{2}(1)=1.08 ; n s$ \\
Education level* & $4.74(1.18)$ & $5.35(.99)$ & $t(41)=1.83 ; n s$ \\
Premorbid IQ & $104.45(13.75)$ & $110.75(10.30)$ & $t(41)=1.67 ; n s$ \\
$\quad$ Number of & $2.43(1.40)$ & - & - \\
$\quad$ hospitalisations & & - & - \\
Length of illness & $6.96(7.38)$ & & - \\
$\quad$ in years) & & - & - \\
BPRS & $9.17(4.29)$ & - & - \\
$\quad$ Positive syndrome & $5.30(2.12)$ & & \\
$\quad$ Negative syndrome & $4.13(1.71)$ & & \\
$\quad$ Disorganisation & $32.65(8.52)$ & & \\
$\quad$ Total & & & \\
Executive function & & & \\
$\quad$ BADS & & & \\
$\quad$ Total score** & $14.04(4.01)$ & $20.05(2.04)$ & $t(41)=5.83 ; p<.001$ \\
$\quad$ WCST & & & \\
$\quad$ categories** & $2.83(1.80)$ & $5.45(1.05)$ & $t(41)=5.72 ; p<.001$ \\
$\quad$ Perseverative errors ${ }^{*}$ & $54.67(19.79)$ & $21.10(16.31)$ & $t(41)=5.91 ; p<.001$ \\
\hline
\end{tabular}

Standard deviations are given in parentheses.

*According to Verhage (1964; where 1 ="lower education"; 7 = university degree").

**Lower scores indicating poorer executive functioning.

${ }^{\#}$ Higher scores indicating poorer executive functioning.

had a first-degree relative with a history of schizophrenia. Sociodemographic characteristics of the control group are also shown in Table 1. All participants gave informed consent before participation. They were paid $€ 10$ (approximately 12.5 US dollars) per hour. The study was approved by the standing ethical committee of the Faculty of Psychology, Maastricht University.

\section{Materials}

Brief Psychiatric Rating Scale (BPRS). We used the 18-item BPRS to measure current symptomatological status of the schizophrenic patients (Overall \& Gorham, 1988). Each BPRS item is rated from 1 ("not present") to 7 ("extremely present"). This scale was originally developed for identifying schizophrenic symptoms, but also includes items tapping, for example, depression. The BPRS was administered by three clinicians who 
were blind as to the neurocognitive status of the patients. Summing items across subscale yields separate scores for negative, positive, and disorganised thought symptomatology. Thus, a negative symptomatology score is obtained by summing scores for the "emotional withdrawal", "motor retardation", and "blunted affect" items. A positive symptomatology score is obtained by summing across the "unusual thought content", "grandiosity", "suspiciousness", and "hallucinatory behaviour" items. The disorganised symptomatology subscale comprises only two symptoms: "conceptual disorganisation" and "mannerisms and posturing" (Moritz et al., 2001).

Premorbid intelligence. Premorbid intelligence was measured with the Dutch Adult Reading Test (Schmand, Lindeboom, \& Harskamp, 1992), which is the Dutch version of the National Adult Reading Test (NART; Nelson, 1982). This task asks participants to read aloud 50 words with irregular spelling. The total score is the number of words that the participant articulates with a correct pronunciation. To estimate premorbid intelligence, scores are compared against normative data.

Adapted Deese/Roediger-McDermott (DRM) paradigm. We developed an adapted version of the DRM paradigm (Deese, 1959; Roediger \& McDermott, 1995) so as to tap memory efficiency, memory errors, and source attributions. Participants were administered a Dutch version of the DRM paradigm consisting of eight selected word lists drawn from a normative study Peters, Jelicic, \& Merckelbach, 2007; Peters, Jelicic, Haas, \& Merckelbach, 2006a). Each list consisted of 15 words (e.g., bed, nap, pillow, snooze) semantically related to a nonpresented critical lure word (e.g., sleep). The lists were read aloud one after the other. To create an internal-external source attribution condition during encoding of word lists, four lists were presented by the experimenter and four by the participant (each read aloud). This was done in an alternating sequence, such that the experimenter read the first list, followed by the participant reading the second, then again the experimenter who read the third and so on. For each participant, lists were randomised across this sequence. Words were presented on a Dell 15-inch laptop computer using PowerPoint. Each word was presented for $1 \mathrm{~s}$ with an interstimulus interval of $1 \mathrm{~s}$. After the eight lists had been presented, participants were asked to complete a filler task. Next, participants had an old/new recognition task consisting of the eight critical lures of the studied lists completely intermixed with 24 study words (the first, eight, and tenth word of each studied list) and 16 unrelated (i.e., new) lures taken from nonpresented lists. Only words that were in no way associated with the words in the studied lists were used as unrelated lures. For each of the 48 recognition task items, the participant was instructed to provide three responses: (a) old/new decision; (b) source 
attribution: That is, when the word was recognised as old, participants had to determine who had read this word aloud-the experimenter or the participant; (c) memory confidence: Here, participants were asked to rate on an 11-point scale (anchor points: $0=$ "I really don't know" to $10=$ "absolutely convinced") how confident they were concerning their old/new and source attribution decisions.

Wisconsin Card Sorting Test (WCST). To tap executive functions, participants were administered a computerised version of the WCST (128 test trials; Heaton et al., 1993). This task was used to measure executive control and working memory (Hartman, Steketee, Silva, Lanning, \& Andersson, 2003). Stimulus material was presented on a Dell 15-inch laptop using E-prime software (www.pstnet.com; Psychology Software Tools). In this task, participants have to sort a deck of cards into four piles, each marked by a key card. Each card consists of one of four designs that appear in one of four different colours (red, green, yellow, or blue), and in one of four forms (triangles, crosses, stars, or circles). Although each card can be sorted according to one of the three dimensions (colour, form or number) at any given point in the test, only one dimension is correct. The sorting rule must be inferred from feedback provided on the computer screen (either "correct" or "incorrect") given after each card. This sorting rule changes without warning after 10 consecutive correct sorts and the test continues until each sorting rule is used twice (in the order colour, form, and number). In the present study, we calculated the WCST parameters "categories completed" (0-6), and "number of perseverative errors".

Behavioural Assessment of the Dysexecutive Syndrome (BADS). The BADS (Wilson et al., 1996; see Krabbendam \& Kalff, 1998, for a Dutch version) is a well-established method for assessing executive functions in schizophrenic patients (Krabbendam, de Vugt, Derix, \& Jolles, 1999). It presents the participant with a series of six unstructured tasks that are designed to reflect daily situations. These tasks intend to measure planning of behaviour in the face of competing information. The BADS comprises the Rule Shift Cards Test (requiring shifts from simple to complex rules), the Action Program Test (practical problem solving), the Key Search Test (searching strategies), the Temporal Judgement Test (time judgements), the Zoo Map Test (route planning), and the Modified Six elements Test (ability to plan, organise, and monitor behaviour). For each of the tasks, a summary profile score is obtained (range $0-4$ ) and these are summed up to obtain a total profile score $($ maximum $=24)$, with higher scores indicating better planning capacities. This total profile score will be used in the present experiment. 


\section{Procedure}

Participants were tested individually in a quiet room. Before testing, all participants received a semistructured interview to verify the absence of exclusion criteria. Subsequently, participants were administered the BPRS (patients only), NART, WCST, and BADS. Next, participants were given the following instruction: "In the current experiment, I will present some lists of words to you. Half of the lists will be read by me. For the other half of the lists, I would like you to read aloud the words presented on the computer screen. I will start with the first list, after which you will have to read aloud the next list, followed by a list read aloud by me, and so on." This was followed by a filler task (unrelated questionnaire) and finally the recognition test of the DRM was presented.

\section{Statistical analyses}

Three different categories of memory indices were derived: memory efficiency, memory errors, and source attributions. Memory efficiency was defined as the proportion hits. Proportion hits was obtained by dividing the number of recognised old words by the total number of old words on recognition test (i.e., 24). We also calculated proportion false alarms (memory errors), which was defined as number of new words recognised as old divided by 24 . For both categories of new words (i.e., new unrelated words and critical lure words), a false alarm index was also separately calculated. Attributing old words presented by either the experimenter or participant to their correct source was defined as correct source attribution. Accordingly, source misattributions (i.e., incorrect source attributions) were defined as self-presented items that were misattributed to the experimenter (self to experimenter) or experimentergenerated items that participants misattributed to themselves (experimenter to self).

Following the Two-High Threshold theory (Corwin, 1994; Snodgrass \& Corwin, 1988), we calculated discrimination index (memory efficiency; $P r$ ) and response bias index (memory errors; $\mathrm{Br}$ ), as measures of accurate and biased discrimination between targets (i.e., old items) and distractors (i.e., new items), respectively. These indices were also calculated for the source attribution measures (source $\mathrm{Pr}$ and $\mathrm{Br}$ ). In doing so, we took the number of erroneous answers into account. Thus, discrimination index was defined as: (number of hits $+0.5 /$ number of targets +1 ) - (number of false alarms $+0.5 /$ number of distractors +1$)$. Response bias was defined as: (number of false alarms $+0.5 /$ number of discractors +1$) /(1-$ discrimination index). 
For all analyses, significance level was set at 5\%, two-tailed. As there was no dependency between recognition variables, two-way analysis of variance (ANOVA) with group (control vs. schizophrenia) as between-subject factor and recognition state (hits vs. false alarms critical lures vs. false alarms new) as within-subject factor were carried out. These were followed by independent samples $t$-tests. When dependency was present, independent samples $t$-tests were carried out to compare groups with regard to the different memory indices and confidence ratings. A two-way ANOVA was also carried out for $\mathrm{Pr}$ indices for the different recognition states, with group status (control vs. schizophrenia) as between-subject factor and discrimination indices $(P r$ hits-false alarm critical lures vs. $P r$ hits-false alarms new vs. $P r$ false alarms critical lures-new) as repeated measure factor. A similar analysis was carried out for the response bias indices $(B r$ hits-false alarm critical lures vs. $B r$ hits-false alarms new vs. $B r$ false alarms critical luresnew). Furthermore, for the subsample of schizophrenic patients, correlation analyses (Pearson-product moment) were carried out between BPRS scores and the different memory indices. Multiple linear regression analyses (Enter method) were performed to explore the contribution of neurocognitive functions (BADS, WCST) to memory efficiency (hits and $\mathrm{Pr}$ indices), memory errors (false alarms and $\mathrm{Br}$ indices), and source attributions (incorrect source attribution, source $\mathrm{Pr}$, and source $\mathrm{Br}$ ). As measures of effect size, Cohen's $d$ ( $t$-tests) and partial eta squared $\left(\eta_{\mathrm{p}}^{2}\right.$; analysis of variance) were calculated.

\section{RESULTS}

\section{Demographic data}

As can be seen in Table 1, patients and controls did not differ in terms of gender distribution, age, premorbid intelligence level, and educational level. Test scores of the neurocognitive measures (WCST and BADS) are also shown in Table 1.

\section{Encoding conditions}

Before pooling the data across the two encoding conditions (experimenter read vs. participant read word lists), the potential confounding effect of encoding conditions on recognition performance of schizophrenic and control participants was tested. A significant interaction between group and encoding condition, with schizophrenic patients being more sensitive to differences in encoding conditions compared to controls would be evidence for such a confounding effect. To test this, two 2 (group status) $\times 2$ 
(experimenter read vs. participant read word lists) ANOVAs with repeated measures on the last factor were carried out for memory efficiency (hits) and memory errors (total false alarms). The critical interactions remained nonsignificant, both $F$ s $(1,41)<2.0$, both $p$ s $>.05$, indicating that the two encoding conditions did not produce differential effects on memory efficiency and errors for patients and controls. For this reason, pooling the data across encoding conditions was appropriate.

\section{Memory efficiency and memory errors}

A 2 (group status) $\times 3$ (recognition state: hits vs. false alarms critical lures vs. false alarms new) ANOVA was carried out with repeated measures on the last factor. This yielded a significant main effect of group status, $F(1,41)=6.42, p=.01, \eta_{\mathrm{p}}^{2}=.14$, and recognition state, $F(2,82)=577.49$, $p<.001, \eta_{\mathrm{p}}^{2}=.93$. The interaction effect of group by recognition state was also significant, $F(2,82)=10.34, p<.001, \eta_{\mathrm{p}}^{2}=.20$; see Figure 1 . These were followed by independent samples $t$-tests for the memory efficiency and error indices. As can be seen in Table 2 (including $t$-values and Cohen's $d$ ), schizophrenic patients made significantly fewer hits than controls. These patients also more often made false alarms for new unrelated words as compared to control participants. On the other hand,

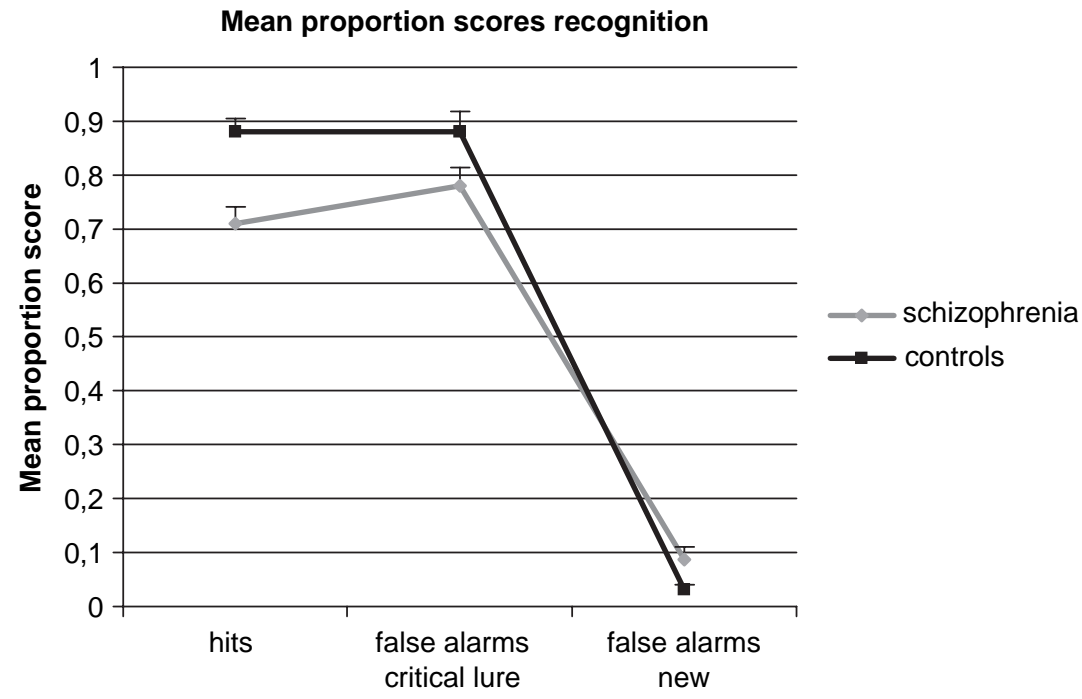

Figure 1. Mean proportion scores for hits, false alarms of critical lures and false alarms new for schizophrenic patients and control participants. Standard errors of mean (SEM) are presented in T bars. 
TABLE 2

Mean proportion scores and standard deviations of memory efficiency, memory error, source attribution, and two-high threshold indices for schizophrenic patients and healthy control participants; statistics ( $t$-values) and effect sizes (Cohen's $d$ ) are also given

\begin{tabular}{|c|c|c|c|c|}
\hline Variable & $\begin{array}{c}\text { Schizophrenic } \\
\text { patients } \\
(n=23) \\
M(S D)\end{array}$ & $\begin{array}{c}\text { Control } \\
\text { participants } \\
(n=20) \\
M(S D)\end{array}$ & $\begin{array}{l}\text { Statistics } \\
t(41)=\end{array}$ & $\begin{array}{c}\text { Cohen's } \\
\quad d\end{array}$ \\
\hline \multicolumn{5}{|l|}{ Memory efficiency } \\
\hline Hits & $0.71(0.16)$ & $0.88(0.11)$ & $4.09, p<.001$ & 1.24 \\
\hline \multicolumn{5}{|l|}{ Discrimination index $(\mathrm{Pr})$} \\
\hline $\begin{array}{l}P r \text { hits vs. false alarm } \\
\text { critical lures }\end{array}$ & $-0.04(0.17)$ & $0.03(0.13)$ & $1.54, p>.05$ & 0.46 \\
\hline $\operatorname{Pr}$ hits vs. false alarm new & $0.59(0.17)$ & $0.81(0.11)$ & $4.96, p<.001$ & 1.54 \\
\hline $\begin{array}{l}P r \text { false alarm critical lures } \\
\text { vs. new }\end{array}$ & $0.64(0.17)$ & $0.78(0.16)$ & $2.86, p<.01$ & 0.85 \\
\hline \multicolumn{5}{|l|}{ Memory errors } \\
\hline False alarm critical lures* & $0.78(0.16)$ & $0.88(0.17)$ & $2.02, p=.05$ & 0.61 \\
\hline False alarm new** & $0.09(0.11)$ & $0.03(0.04)$ & $2.10, p=.04$ & 0.72 \\
\hline Total false alarm*** & $0.32(0.10)$ & $0.32(0.07)$ & $0.10, p>.05$ & 0.11 \\
\hline \multicolumn{5}{|l|}{ Bias index $(B r)$} \\
\hline $\begin{array}{l}B r \text { hits vs. false alarm } \\
\text { critical lures }\end{array}$ & $0.72(0.12)$ & $0.86(0.12)$ & $3.97, p<.001$ & 1.17 \\
\hline $\begin{array}{l}B r \text { hits vs. false alarm } \\
\text { new }\end{array}$ & $0.27(0.20)$ & $0.35(0.20)$ & $1.37, p>.05$ & 0.40 \\
\hline $\begin{array}{l}B r \text { false alarm critical } \\
\text { lures vs. new }\end{array}$ & $0.30(0.21)$ & $0.33(0.20)$ & $0.48, p>.05$ & 0.15 \\
\hline \multicolumn{5}{|l|}{ Source attribution } \\
\hline Correct source attribution & $0.39(0.13)$ & $0.64(0.15)$ & $5.68, p<.001$ & 1.78 \\
\hline Incorrect source attribution & $0.32(0.12)$ & $0.24(0.11)$ & $2.17, p=.04$ & 0.69 \\
\hline Source false alarms Self-Exp. & $0.42(0.19)$ & $0.30(0.13)$ & $2.36, p=.02$ & 0.74 \\
\hline Source false alarms Exp.-Self & $0.21(0.17)$ & $0.18(0.15)$ & $0.71, p>.05$ & 0.19 \\
\hline Source $\mathrm{Pr}$ & $0.08(0.19)$ & $0.39(0.23)$ & $4.80, p<.001$ & 1.47 \\
\hline Source $B r$ & $0.35(0.09)$ & $0.41(0.07)$ & $2.55, p=.02$ & 0.74 \\
\hline
\end{tabular}

\footnotetext{
*Number of false recognition critical lures/8; **Number of false recognition new/16; $* * *($ Number of false recognition critical lures + number of false recognition new)/24. Self - Exp. $=$ Self - Experimenter; Exp - Self $=$ Experimenter - Self.

control participants more often accepted critical lures compared to schizophrenic participants.
}

\section{Discrimination index and response bias index}

Discrimination indices $(\mathrm{Pr})$ and response bias indices $(\mathrm{Br})$ were calculated for hits vs. false alarms critical lures, hits vs. false alarms new, and false 
alarms critical lures vs. false alarms new (based on Hudon et al., 2006). These indices were analysed using a 2 (group status) $\times 3$ (discrimination state: $\operatorname{Pr}$ hits-false alarms critical lures vs. $P r$ hits-false alarms new vs. $P r$ false alarm critical lures-new) ANOVA with repeated measures on the last factor, yielding a significant main effect of group, $F(1,41)=24.57, p<$ $.001, \eta_{\mathrm{p}}^{2}=.38$, and discrimination state, $F(2,82)=327.74, p<.001, \eta_{\mathrm{p}}^{2}=$ 89. However, the interaction effect remained nonsignificant. This analysis was followed up by independent samples $t$-tests. Groups differed with regard to $\operatorname{Pr}$ hits vs. false alarms new and $\operatorname{Pr}$ false alarm critical lures vs. new, in that patients were significantly worse at discriminating between these memory indices (see Table 2).

For the response bias indices, a similar 2 (group status) $\times 3$ (response bias state: $\mathrm{Br}$ hits-false alarms critical lures vs. $\mathrm{Br}$ hits-false alarms new vs. $B r$ false alarm critical lures-new) ANOVA was analysed. A significant main effect emerged for the response bias state, $F(2,82)=$ 202.32, $p<.001, \eta_{\mathrm{p}}^{2}=.83$ ]. For the group status, a marginal significant main effect emerged, $F(1,41)=3.71, p=.06, \eta_{\mathrm{p}}^{2}=.08$. The interaction between group status and response bias state remained nonsignificant. Overall, both groups showed a liberal response bias $(B r)$ when comparing hits vs. false alarms of critical lures. However, controls displayed a more liberal $B r$ than schizophrenic patients (see Table 2). For the other two response biases ( $\mathrm{Br}$ hits vs. false alarms new and $\mathrm{Br}$ false alarms critical lures vs. new), both groups showed a more conservative response bias. However, there were no differences between the two groups on these indices.

\section{Source attribution}

Table 2 shows source attribution data of both groups, including statistics ( $t$-values) and effect sizes (Cohen's $d$ ). Overall, control participants were significantly better in attributing the correct source to the old items than were patients. Total incorrect source attribution differed between the groups. When differentiating between self-presented and experimenterpresented words, schizophrenic patients more often attributed self-presented words to the experimenter, compared to control participants. The groups did not differ in attributing words presented by the experimenter to themselves. Groups also differed with regard to source $\mathrm{Pr}$ and source $\mathrm{Br}$. Relative to controls, patients were significantly worse at discriminating between source targets and distractors (source $\mathrm{Pr}$ ). However, source response bias (source $\mathrm{Br}$ ) was significantly more liberal for the control group as compared to the schizophrenic group. 


\section{Relationship between memory efficiency, memory errors, source attribution, and BPRS}

None of the symptom scores as measured by the BPRS showed significant correlations with hits. For memory errors, a marginally significant correlation was found between BPRS disorganisation and false alarms of new words ( $r=.34, p=.05$, one-tailed). None of the other memory efficiency, memory errors, or source attribution parameters were related to the BPRS subscales (all $r \mathrm{~s}<.20$, all $p \mathrm{~s}>.05$ ).

\section{Confidence ratings}

As can be seen in Table 3 (including $t$-values and Cohen's $d$ ), relative to patients, control participants had more confidence in their hits. For memory errors, control participants showed significantly more confidence in false alarms for critical lure words compared to schizophrenic patients. As for confidence in source decisions, schizophrenic patients showed higher confidence in falsely attributing old words presented by themselves to the experimenter, whereas controls showed more confidence in correct source attribution. All other comparisons remained nonsignificant. None of the confidence parameters correlated with BPRS symptom scores.

\section{Neurocognitive deficits and memory functioning}

As can be seen in Table 1, schizophrenic patients performed worse on the executive function tasks (i.e., WCST and BADS) than controls, all $t \mathrm{~s}$ (41) $>5.00$, all $p \mathrm{~s}<.001$, all $d \mathrm{~s}>1.75$.

We included the neurocognitive measures (i.e., WCST perseverative errors and BADS total score) ${ }^{1}$ into multiple regression analyses (Enter method) to test whether these measures would predict memory efficiency, memory errors, and source attributions (see Table 4). Data of both groups were pooled and then regression analyses were conducted. The analyses were restricted to memory efficiency (hits, $\operatorname{Pr}$ hits-false alarms new, $\mathrm{Pr}$ false alarm critical lures-new), memory errors (false alarms critical lures, false alarms new, and $B r$ hits-false alarms critical lures), and source misattribution (incorrect source attribution, source Self-Experimenter, source $\mathrm{Pr}$, and source $\mathrm{Br}$ ). The results demonstrated that for hits, WCST perseverative errors and BADS total score were significant predictors. The relationship with perseverative errors was negative,

\footnotetext{
${ }^{1}$ WCST categories completed was left out of the regression analyses, because this variable strongly correlated with the other WCST scores $(r>.80, p<.001)$, indicating multicollinearity.
} 
TABLE 3

Means $(S D)$ for source attribution confidence in schizophrenic and control participants; statistics and effect sizes (Cohen's $d$ ) are also given

\begin{tabular}{|c|c|c|c|c|}
\hline & $\begin{array}{c}\text { Schizophrenic } \\
\text { patients }(n=23) \\
M(S D)\end{array}$ & $\begin{array}{c}\text { Control } \\
\text { participants }(n=20) \\
M(S D)\end{array}$ & $\begin{array}{l}\text { Statistics } \\
t(41) ; p\end{array}$ & $\begin{array}{c}\text { Cohen's } \\
d\end{array}$ \\
\hline \multicolumn{5}{|l|}{ Confidence memory efficiency } \\
\hline Hits & $6.90(2.18)$ & $8.30(1.25)$ & $2.60 ; p<.01$ & 0.79 \\
\hline \multicolumn{5}{|l|}{ Confidence memory errors } \\
\hline $\begin{array}{l}\text { False alarm critical } \\
\text { lures }\end{array}$ & $5.37(2.03)$ & $7.16(1.82)$ & $2.97 ; p<.005$ & 0.92 \\
\hline False alarm new & $2.32(2.72)$ & $1.08(1.61)$ & $1.77 ; n s$ & 0.55 \\
\hline Total false alarm & $4.35(1.84)$ & $5.15(1.35)$ & $1.57 ; n s$ & 0.50 \\
\hline \multicolumn{5}{|l|}{ Confidence source attribution } \\
\hline $\begin{array}{l}\text { Correct source } \\
\text { attribution }\end{array}$ & $6.70(2.08)$ & $8.11(1.15)$ & $2.51 ; p<.02$ & 0.78 \\
\hline $\begin{array}{l}\text { Incorrect source } \\
\text { attribution }\end{array}$ & $6.85(1.91)$ & $6.04(1.86)$ & $1.40 ; n s$ & 0.43 \\
\hline Source false alarms Self-Exp. & $7.86(2.69)$ & $5.21(1.17)$ & $4.06 ; p<.001$ & 1.28 \\
\hline Source false alarms Exp. - Self & $5.84(3.30)$ & $6.29(3.80)$ & $0.42 ; n s$ & 0.13 \\
\hline
\end{tabular}

indicating that an increase in perseverative errors was associated with a decrease in memory efficiency. For the BADS test, higher executive functioning scores were associated with an increase in memory efficiency. When these predictors were entered in the regression analysis, the model accounted for $51 \%$ of the variance. The discrimination index ( $\operatorname{Pr}$ hits vs. false alarms new) was predicted by the BADS total score and WCST perseverative errors. For the BADS score, better executive scores were associated with superior discrimination. For the WCST perseverative errors, heightened perseverative errors were accompanied by poor discrimination. This regression model accounted for $58 \%$ of the variance. None of the executive functioning measures entered the regression equations for the other false alarms and source misattribution scores.

When multiple regression analyses were carried out for both groups separately, significant predictors of memory efficiency only emerged in the schizophrenic patient sample. For hits, WCST perseverative errors (negative) and BADS total score (positive) were found to be significant predictors, accounting for $48 \%$ of the variance. Furthermore, BADS total score was a significant predictor of discrimination index ( $\operatorname{Pr}$ hits vs. false alarms new), with higher BADS scores predicting higher $\operatorname{Pr}$ values, accounting for $47 \%$ of the explained variance. For memory errors and source attribution indices, no significant neurocognitive predictors were identified in both groups. 
TABLE 4

Multiple regression analyses predicting memory efficiency (hits and $\operatorname{Pr}$ hits vs. false alarms new, and Pr false alarms critical lure vs. new), memory errors (false alarms critical lures, false alarms new, $B r$ hits vs. false alarms critical lures), and source misattribution (incorrect source attribution, source $P r$, and source $B r$ ) scores on the basis of executive dysfunctions (WCST perseverative errors, BADS total score) for both groups; all independent measures were entered

\begin{tabular}{llrrrr}
\hline Dependent variable & Variables entered at $p<.05$ & $B$ & $S E B$ & $\beta$ & $R^{2}$ \\
\hline Memory efficiency & & & & & \\
Hits & Perseverative errors & -.05 & .02 & -.36 & .51 \\
& BADS total score & .35 & .14 & .42 & \\
$\operatorname{Pr}$ hits vs. false alarms new & Perseverative errors & -.002 & .001 & -.35 & .58 \\
& BADS total score & .02 & .01 & .47 \\
$\operatorname{Pr}$ false alarms critical lure vs. new & No variables entered & & & & \\
Memory errors & & & & \\
False alarm critical lures & No variables entered & & & \\
False alarm new & No variables entered & & & \\
$B r$ hits vs. false alarms critical lures & No variables entered & & & \\
Source attribution & & & & \\
$\quad$ Incorrect source attribution & No variables entered & & & & \\
Source Self-Experimenter & No variables entered & & & & \\
Source $P r$ & No variables entered & & & & \\
Source $B r$ & No variables entered & & & & \\
\hline
\end{tabular}

\section{DISCUSSION}

We found that patients with schizophrenia, relative to controls, showed poorer memory efficiency. Their hit rates were accompanied by a lowered confidence in comparison to the control group. As to false alarms of critical lures, in line with prior research (e.g., Elvevåg et al., 2004; Moritz et al., 2004; Roediger \& McDermott, 1995), both groups showed a substantial number of such false alarms, and also demonstrated at chance performance for discrimination between old words and critical lures. However, and again replicating previous work (Moritz et al., 2004; Weiss et al., 2002), it was the control group that had the highest level of false alarms to critical lures. This was accompanied by heightened confidence. On the other hand, schizophrenic patients more often made false alarms for new lures than controls, therefore also showing decreased discrimination between old and new words. As to the individual source misattribution indices, our findings concur with previous research by Keefe et al. (1999), Moritz et al. (2003), and Vinogradov et al. (1997) in that relative to healthy controls, schizophrenic patients were more prone to recognise self-presented words as presented by the experimenter (internal-external source misattribution) with increased confidence ratings. This misattribution tendency was clearly reflected in the 
source discrimination index, which was significantly lower in the schizophrenic patients than controls (see also Brébion et al., 2002; Henquet, Krabbendam, Dautzenberg, Jolles, \& Merckelbach, 2005). Another important finding of the current study is that executive functioning indices (i.e., WCST perseverative errors and BADS total score) serve as significant predictors of memory efficiency. Yet, none of these neurocognitive measures accounted for source misattributions or memory error scores. As well, in schizophrenic patients, but not in controls, executive dysfunctions predicted memory efficiency.

When overall performance accuracy was taken into account, controls showed a more liberal response bias tendency than schizophrenic patients for hits vs. false alarms of critical lures. For source $B r$, the magnitude of this bias index is similar to those reported in previous research using similar samples (e.g., Brébion et al., 2002; Henquet et al., 2005). However, previous studies did not detect significant differences in response bias between schizophrenic patients and healthy controls. The fact that we did find such differences is probably related to the DRM version that we employed. Thus, the high levels of false alarms of critical lures in particularly controls is most likely the result of a more liberal response bias in this group promoted by the semantically related stimulus material. In contrast, schizophrenic patients' higher false alarm levels for new lures might reflect overall inaccuracy of source monitoring performance, as indicated by their significantly lower $\mathrm{Pr}$ hits vs. false alarms new and source $\mathrm{Pr}$ indices compared to controls.

As to false memories, schizophrenic patients did not falsely recognise critical lures more often than healthy controls. As a matter of fact, the opposite was true. Several studies have described spreading activation in semantic networks as a key feature in eliciting experimentally induced false memories (e.g., Roediger, Balota, \& Watson, 2001). When presented a list of semantically associated words, semantically related, but nonpresented critical lure words will also be activated. It may well be the case that this spreading activation is less marked in schizophrenic patients, resulting in only weak activation of the semantic associate and, as a consequence, reduced levels of false recognition of critical lures (see also Elvevåg et al., 2004; Moritz et al., 2004). A closely related view is that the lower levels of false memories in schizophrenic patients have to do with their difficulty in dealing with context and redundant information (e.g., Waters, Maybery, Badcock, \& Michie, 2004). Thus, control participants would profit from the context of semantically related material, but the other side of the coin is that this makes them vulnerable to this specific class of false memories. To the extent that schizophrenic patients cannot profit from semantic context, this makes them relatively immune to this category of false memories. Still another possibility may be that encoding deficits not only lead to a decrease in correct recognition of old words, but may also reduce semantically related 
false recognition, because lack of stable memory representations means that the weak memory traces cannot converge onto the critical lure word. ${ }^{2}$

As for source misattributions, we found that relative to controls, schizophrenic patients more often identified self-presented words as presented by the experimenter. This externalising tendency has also been found in earlier work (e.g., Moritz et al., 2003). Replicating Moritz et al. (2003), this source misattribution was not correlated with positive symptoms or poor executive functioning. It is true that control participants also committed source misattributions. However, their lowered confidence ratings indicate that they attached some sort of "nontrustworthiness" tag to their misattributions. Another antecedent of controls' misattributions might be their source response bias. In contrast, schizophrenic patients make more source misattributions and they do this with high confidence. One important antecedent in making correct source attributions is the amount of perceptual detail/contextual information that is encoded, with correct memory traces exhibiting many distinctive features (e.g., Johnson et al., 1993). Schizophrenic patients show clear deficits in the encoding of distinctive perceptual features (Brébion et al., 2005). Meanwhile such features serve as landmarks in classifying an event as presented by themselves or by external sources. In schizophrenic patients, these landmarks are lacking, making them more vulnerable to this specific type of source misattribution.

Previous research by Brébion et al. (2005) found poor correct recognition in schizophrenia to be related to slower processing speed and impaired selective attention. These impairments in automated cognitive functions may undermine efficient encoding, thereby impeding serial learning and semantic organisation of, for example, word lists. The present study shows that executive control, as an effortful process, also plays a role in recognition memory. Although this factor significantly predicted memory efficiency when both subsamples were pooled, its predictive value was mainly carried by the group of schizophrenic patients. Executive dysfunctions (increase in perseverative errors during WCST and poor planning function during BADS) in schizophrenic patients have been well documented and there is every reason to suspect that they originate from reduced activity in the prefrontal cortex (e.g., Li, 2004; Seidman et al., 1994). Interestingly, damage to the prefrontal regions - reflected in executive dysfunctions and working memory impairments - results in poor recollection of the contextual details (distinctive perceptual features) of previously learned information (e.g., Peters et al., 2006b). Indeed, the most parsimonious explanation for the

\footnotetext{
${ }^{2}$ A negative correlation was found between misses and false alarms of critical lure words when both samples were pooled ( $r=-.49, p<.001$, two-tailed), thereby underscoring this possible explanation.
} 
pattern found in the current study is that schizophrenic patients' problems with executive control and planning leads to poor binding and difficulties in holding online the set of semantic associates in the word lists. Eventually, this results in poor encoding (superficial processing) of the word lists. Indeed, executive control and working memory are important in organising and clustering networks of semantic associates. Problems with executive control and working memory will subsequently lead to lower memory efficiency. Thus, our findings show that an extension of the current model by Brébion et al. (2005) is required in that not only automated cognitive functions (i.e., slower processing speed and selective attention) affect memory efficiency, but also effortful neurocognitive functions (i.e., executive dysfunctions).

In the current study, we found that poor executive functioning, as indexed by WCST and BADS, was linked to poor memory efficiency. It might well be the case that this link is highly specific. That is to say, performance on the WCST and BADS critically depends on semantic processing (e.g., Heaton et al., 1993), and thus one could argue that poor semantic processing, rather than poor executive functioning per se, accounts for the link between performance on our executive functioning tasks and memory efficiency. Clearly, this point warrants further study. More precisely, future research could profit from including semantic processing measures (e.g., semantic fluency tests) along with executive functioning tasks to further delineate the specific contributions of poor semantic processing abilities and executive deficits to schizophrenic patients' memory aberrations.

In contrast to previous research (Brébion et al., 2000, 2002), we did not find a significant relationship between positive symptomatology and specific (source) memory errors. This could be due to the fact that schizophrenic patients in this study were mostly stabilised chronic patients. As a group, patients exhibited little variability in BPRS scores. Future research on how positive symptoms relate to source misattributions, with larger and more diverse samples, seems to be necessary.

One limitation of the present study was that all our schizophrenic patients were receiving psychotropic medication. Theoretically, differences in memory performance between patients and healthy controls could be confounded by medication. However, research on the impact of medication status on episodic memory has produced mixed results, with most recent studies reporting no significant effect (e.g., Aleman et al., 1999; Mortimer, 1997) or even cognitive benefits (Hagger et al., 1993).

A second limitation is that we compared memory performance of schizophrenic patients to that of healthy controls. There are other clinical groups that are known to exhibit memory dysfunctions (e.g., memory distrust in obsessive-compulsive disordered patients; Radomsky, Gilchrist, \& Dussault, 2006). Thus, further research in this domain should preferably 
include other clinical groups, although the practical difficulties of this are obvious.

Finally, one could argue that in combination with the small sample, our procedure of eight word lists subdivided into two encoding conditions, might not have been sensitive enough (i.e., was underpowered) to detect group differences in all types of false alarms. However, when comparing our findings with previous studies looking at memory functioning in schizophrenia (e.g., Elvevåg et al., 2004; Keefe et al., 1999; Moritz et al., 2003, 2004; Vinogradov et al., 1997; Weiss et al., 2002), the similarities in the pattern of memory aberrations (i.e., lowered efficiency, fewer false alarms of critical lures, internal-external source misattributions) documented for schizophrenic patients is striking. Nonetheless, it would be wise to increase sample size and the number of word lists and related lure words in future research.

To our knowledge, this is the first study that made an attempt to document the full range of memory aberrations of schizophrenic patients with one paradigm. Recognition memory (efficiency, errors, and source attribution) was found to be markedly impaired in patients with schizophrenia, with executive dysfunctions better predicting memory efficiency than symptomatology. These findings provide further evidence for explaining schizophrenics' memory impairments in terms of fundamental neurocognitive deficits like executive dysfunctions.

Manuscript received 3 June 2006

Revised manuscript received 20 March 2007

\section{REFERENCES}

Aleman, A., Hijman, R., de Haan, E. H. F., \& Kahn, R. S. (1999). Memory impairment in schizophrenia: A meta-analysis. American Journal of Psychiatry, 156, 1358-1366.

American Psychiatric Association. (1994). Diagnostic and statistical manual of mental disorders (4th ed.). Washington, DC: American Psychiatric Association Press.

Brébion, G., Amador, X., David, A., Malaspina, D., Sharif, Z., \& Gorman, J. M. (2000). Positive symptomatology and source-monitoring failure in schizophrenia: An analysis of symptomspecific effects. Psychiatry Research, 95, 119-131.

Brébion, G., Gorman, J. M., Amador, X., Malaspina, D., \& Sharif, Z. (2002). Source monitoring impairments in schizophrenia: Characterization and associations with positive and negative symptomatology. Psychiatry Research, 112, 27-39.

Brébion, G., Gorman, J. M., Malaspina, D., \& Amador, X. (2005). A model of verbal memory impairments in schizophrenia: Two systems and their associations with underlying cognitive processes and clinical symptoms. Psychological Medicine, 35, 133-142.

Corwin, J. (1994). On measuring discrimination and response bias: Unequal numbers of targets and distractors and two classes of distractors. Neuropsychology, 8, 110-117.

Deese, J. (1959). On the prediction of occurence of particular verbal intrusions in immediate recall. Journal of Experimental Psychology, 58, 17-22. 
Dodson, C. S., \& Schacter, D. L. (2002). The cognitive neuropsychology of false memories: Theory and data. In A. D. Baddeley, M. D. Kopelman, \& B. A. Wilson (Eds.), Handbook of memory disorders (pp. 343-362). Chichester, UK: Wiley.

Elvevåg, B., Fisher, J. E., Weickert, T. W., Weinberger, D. R., \& Goldberg, T. E. (2004). Lack of false recognition in schizophrenia: A consequence of poor memory? Neuropsychologia, 42, 546-554.

Hagger, C., Buckley, P., Kenny, J. T., Friedman, L., Ubogy, D., \& Meltzer, H. Y. (1993). Improvement in cognitive functions and psychiatric symptoms in treatment-refractory schizophrenic patients receiving clozapine. Biological Psychiatry, 34, 702-712.

Hartman, M., Steketee, M. C., Silva, S., Lanning, K., \& Andersson, C. (2003). Wisconsin Card Sorting Test performance in schizophrenia: The role of working memory. Schizophrenia Research, 63, 201-217.

Heaton, R. K., Chelune, G. J., Talley, J. L., Kay, G. G., \& Curtiss, G. (1993). Wisconsin Card Sorting Test manual: Revised. Odessa, FL: Psychological Assessment Resources.

Henquet, C., Krabbendam, L., Dautzenberg, J., Jolles, J., \& Merckelbach, H. (2005). Confusing thoughts and speech: Source monitoring and psychosis. Psychiatry Research, 133, 57-63.

Heinrichs, R. W., \& Zakzanis, K. K. (1998). Neurocognitive deficit in schizophrenia: A quantitative review of the evidence. Neuropsychology, 12, 426-445.

Hudon, C., Belleville, S., Souchay, C., Gély-Nargeot, M. C., Chertkow, H., \& Gauthier, S. (2006). Memory for gist and detail information in Alzheimer's disease and mild cognitive impairment. Neuropsychology, 20, 566-577.

Johnson, M. K., Hashtroudi, S., \& Lindsay, D. S. (1993). Source monitoring. Psychological Bulletin, 114, 3-28.

Keefe, R. S., Arnold, M. C., Bayen, U. J., \& Harvey, P. D. (1999). Source monitoring deficits in patients with schizophrenia: A multinomial modeling analysis. Psychological Medicine, 29, 903-914.

Krabbendam, L., de Vugt, M. E., Derix, M. M. A., \& Jolles, J. (1999). The behavioural assessment of the dysexecutive syndrome as a tool to assess executive functions in schizophrenia. The Clinical Neuropsychologist, 13, 370-375.

Krabbendam, L., \& Kalff, A. C. (1998). The Behavioural Assessment of the Dysexecutive Syndrome-Dutch version. Lisse, The Netherlands: Swets \& Zeitlinger.

Li, C.-S. R. (2004). Do schizophrenia patients make more perseverative than non-perseverative errors on the Wisconsin Card Sorting Test? A meta-analytic study. Psychiatry Research, 129, 179-190.

McKenna, P. J., McKay, A. P., \& Laws, K. (2000). Memory in functional psychosis. In G. E. Berrios \& J. R. Hodges (Eds.), Memory disorders in psychiatric practice (pp. 234-267). Cambridge, UK: Cambridge University Press.

McKenna, P. J., Ornstein, T., \& Baddeley, A. (2002). Schizophrenia. In A. D. Baddeley, M. D. Kopelman, \& B. A. Wilson (Eds.), Handbook of memory disorders (pp. 413-435). Chichester, UK: Wiley.

McKenna, P. J., Tamlyn, D., Lund, C. E., Mortimer, A. M., Hammond, S., \& Baddeley, A. D. (1990). Amnesic syndrome in schizophrenia. Psychological Medicine, 20, 967-972.

Moritz, S., Andresen, B., Jacobsen, D., Mersmann, K., Wilke, U., Lambert, M., et al. (2001). Neuropsychological correlates of schizophrenic syndromes in patients treated with atypical neuroleptics. European Psychiatry, 16, 354-361.

Moritz, S., \& Woodward, T. S. (2002). Memory confidence and false memories in schizophrenia. Journal of Nervous and Mental Disease, 190, 641-643.

Moritz, S., Woodward, T. S., Cuttler, C., Whitman, J. C., \& Watson, J. M. (2004). False memories in schizophrenia. Neuropsychology, 18, 276-283.

Moritz, S., Woodward, T. S., \& Ruff, C. C. (2003). Source monitoring and memory confidence in schizophrenia. Psychological Medicine, 33, 131-139. 
Mortimer, A. M. (1997). Cognitive function in schizophrenia: Do neuroleptics make a difference? Pharmacology. Biochemistry and Behavior, 56, 789-795.

Nelson, H. E. (1982). The National Adult Reading Test. Windsor, UK: NFER-Nelson.

Nienow, T. M., \& Docherty, N. (2004). Internal source monitoring and thought disorder in schizophrenia. Journal of Nervous and Mental Disease, 192, 696-700.

Overall, J. E., \& Gorham, D. R. (1988). Brief Psychiatric Rating Scale (BPRS): Recent developments in ascertainment and scaling. Psychopharmacology Bulletin, 24, 97-99.

Peters, M. J. V., Jelicic, M., Haas, N., \& Merckelbach, H. (2006a). Mild executive dysfunctions in undergraduates are related to recollecting words never presented. International Journal of Neuroscience, 116, 1065-1077.

Peters, M. J. V., Jelicic, M., \& Merckelbach, H. (2006b). Neuropsychology and pseudomemories. In J. R. Dupri (Ed.), Focus on neuropsychology research (pp. 163-184). Hauppauge, NY: Nova Science Publishers.

Peters, M. J. V., Jelicic, M., \& Merckelbach, H. (2007). Inducing false memories: A Dutch version of the Deese/Roediger-McDermott paradigm. Manuscript submitted for publication .

Radomsky, A. S., Gilchrist, P. T., \& Dussault, D. (2006). Repeated checking really does cause memory distrust. Behaviour Research and Therapy, 44, 305-316.

Roediger, H. L., III, Balota, D. A., \& Watson, J. M. (2001). Spreading activation and arousal of false memories. In H. L. Roediger, J. S. Nairne, I. Neath, \& A. M. Suprenant (Eds.), The nature of remembering: Essays in honor of Robert G. Crowder (pp. 95-115). Washington, DC: American Psychological Association.

Roediger, H. L., III,, \& McDermott, K. B. (1995). Creating false memories: Remembering words not presented in lists. Journal of Experimental Psychology: Learning, Memory, and Cognition, $21,803-814$.

Schmand, B., Lindeboom, J., \& van Harskamp, F. (1992). Dutch Adult Reading Test. Lisse, The Netherlands: Swets \& Zeitlinger.

Seidman, L. J., Yurgelun-Todd, D., Kremen, W. S., Woods, B. T., Goldstein, J. M., Faraone, S. V., et al. (1994). Relationship of prefrontal and temporal lobe MRI measures to neuropsychological performance in chronic schizophrenia. Biological Psychiatry, 35, 235-246.

Snodgrass, J. G., \& Corwin, J. (1988). Pragmatics of measuring recognition memory: Applications to dementia and amnesia. Journal of Experimental Psychology: General, 117, 34-50.

Verhage, F. (1964). Intelligentie en leeftijd [Intelligence and age]. Assen, The Netherlands: Van Gorcum.

Vinogradov, S., Willis-Shore, J., Poole, J. H., Marten, E., Ober, B. A., \& Shenaut, G. K. (1997). Clinical and neurocognitive aspects of source monitoring errors in schizophrenia. American Journal of Psychiatry, 154, 1530-1537.

Waters, F. A. V., Maybery, M. T., Badcock, J. C., \& Michie, P. T. (2004). Context memory and binding in schizophrenia. Schizophrenia Research, 68, 119-125.

Weinberger, D. R., Egan, M. F., Bertolino, A., Callicott, J. H., Mattay, V. S., Lipska, B. K., et al. (2001). Prefrontal neurons and the genetics of schizophrenia. Biological Psychiatry, 50, $825-844$.

Weiss, A. P., Dodson, C. S., Goff, D. C., Schacter, D. L., \& Heckers, S. (2002). Intact suppression of increased false recognition in schizophrenia. American Journal of Psychiatry, 159, 1506-1513.

Wilson, B. A., Alderman, N., Burgess, P. W., Emslie, H. E., \& Evans, J. J. (1996). Behavioural Assessment of the Dysexecutive Syndrome. Bury St Edmunds, UK: Thames Valley Test Company. 